\title{
Liquid biopsy for lung cancer immunotherapy (Review)
}

\author{
LIANG-LIANG CAI and JIE WANG
}

\begin{abstract}
Department of Medical Oncology, National Cancer Center/National Clinical Research Center for Cancer/Cancer Hospital, Chinese Academy of Medical Sciences and Peking Union Medical College, Beijing 100021, P.R. China
\end{abstract}

Received February 5, 2018; Accepted January 17, 2019

DOI: $10.3892 / \mathrm{ol} .2019 .10166$

\begin{abstract}
The recent successful use of the immune checkpoint inhibitors (CPIs) anti-programmed death receptor-1 (PD-1)/PD-1 ligand 1 in clinical trials indicates their crucial role in obtaining an effective cancer immune therapy. These CPIs have been identified to have an effective therapeutic response, particularly in tumors with high tumor mutation burden. Targeting private somatic mutations encoding immunogenic neoantigens (neo-Ags) has been developed as an autologous gene therapy. T-cell receptor-engineered $\mathrm{T}$ cells targeting neo-Ags are a novel option for adoptive cell therapy used for the treatment of lung cancer. However, not all patients experience an effective response from immunotherapy. Although the resistance mechanism of CPIs has been reported, its association with other treatment methods during systemic anticancer therapy remains unclear, particularly the treatment options following the emergence of drug resistance in lung cancer. The potential biomarkers used for liquid biopsy may assist in the identification of patients who would benefit the most from immunotherapy. Attempts to identify potential biomarkers for predicting clinical response to immunotherapy are underway. With regard to liquid biopsy, the present review summarizes and discusses the lung cancer management of immunotherapy for precision medicine by reviewing recent literature and associated clinical trials.
\end{abstract}

Correspondence to: Professor Jie Wang, Department of Medical Oncology, National Cancer Center/National Clinical Research Center for Cancer/Cancer Hospital, Chinese Academy of Medical Sciences and Peking Union Medical College, 17 Pan Jia Yuan Nan Li, Chaoyang, Beijing 100021, P.R. China

E-mail: zlhuxi@163.com

Abbreviations: TCR, T-cell receptor; CPI, checkpoint inhibitor; NSCLC, non-small cell lung cancer; TMB, tumor mutation burden; CTLA4, cytotoxic T-lymphocyte-associated protein 4; TME, tumor microenvironment; GZM, granzyme; neo-Ag, neoantigen; MHC, major histocompatibility complex; TIL, tumor-infiltrating lymphocyte; NGS, next-generation sequencing; HPLC-MS, high-performance liquid chromatography-mass spectrometry

Key words: checkpoint inhibitors, tumor mutation burden, liquid biopsy, $\mathrm{T}$ cells, prognosis, lung cancer, neoantigens

\section{Contents}

1. Introduction

2. Cancer-immunity cycle and immune CPI response and resistance

3. Biomarkers associated with liquid biopsy for lung cancer immunotherapy

4. TCR-engineered adoptive therapy targeting neo-Ags for lung cancer

5. Discussion and conclusions

\section{Introduction}

Checkpoint inhibitors (CPIs), adoptive cell transfer and administration of the cytokine interleukin 2, have been developed as effective clinical cancer immunotherapies, with no clear identification of the immunogenic targets in human types of cancer. Since ipilimumab, an immune CPI for CTLA4 was approved in the United States in 2011 (1), CPIs, as novel anticancer agents, have indicated great promise for effective lung cancer therapy (2-7). Among them, the programmed death receptor-1 (PD-1)/PD-1 ligand 1 (PD-L1) pathway is a key immune checkpoint (8). Anti-PD-1 monoclonal antibodies have been approved by the Food and Drug Administration in the USA for treatments of a number of solid cancer types, including advanced non-small cell lung cancer (NSCLC) (9-15). In addition, antibodies against PD-L1 have indicated an effective clinical response in patients with NSCLC (16).

Spigel et al reported an association of tumor mutation burden (TMB) with the effect of CPI therapy (17). Anagnostou et al (18) have depicted the evolving landscape of tumor neoantigens (neo-Ags) and immunogenic products of somatic mutations in patients with NSCLC, who exhibit resistance following initial response to CPIs with anti-PD-1 or anti-PD-1/anti-cytotoxic T-lymphocyte-associated protein 4 (CTLA4) antibodies. This study provided insights into the dynamics of mutational landscapes during CPI therapy and discusses implications for the development of immunotherapies that target private tumor neo-Ags. Increasing clinical evidence has indicated that neo-Ags will become the targets associated with successful immunotherapy.

Liquid biopsy was successful for its utility in molecularly targeted therapy (19-21). Unlike surgical biopsies, it is simple and non-invasive, allowing, through a simple blood sample, an extensive amount of information to be obtained about 
the tumor. Clonal evolution with driver gene mutations (e.g., EGFR, EML4-ALK) has allowed lung cancer to become suitable for liquid biopsy in molecularly target therapy (22). With the use of CPIs, $30 \%$ of patients with lung cancer, whose tumor PD-L1 expression is $>50 \%$ (23), might benefit from better prognosis. However, at the European Society for Medical Oncology 2016 congress, the results indicated that molecularly targeted drugs are available only for subgroups of patients with cancer, and that CPIs are effective in 20-30\% of patients, who have not been indicated to have any of the available predictive markers, including PD-L1 and PD-1 (24). However, useful biomarkers that can facilitate the monitoring of lung cancer immunotherapy, particularly liquid biopsy biomarkers, are still lacking (25). In the present review, the immune CPI response/resistance and the change in clinical therapy strategy based on the cancer-immunity cycle, the liquid biopsy biomarkers for lung cancer immunotherapy and a T-cell receptor (TCR)-engineered adoptive therapy targeting neo-Ags was conducted for patients with lung cancer by using liquid biopsy material-circulating tumor cells or circulating tumor DNA (ctDNA) are discussed. The current literature and clinical trials were highlighted regarding the use of liquid biopsies in lung cancer immunotherapy.

\section{Cancer-immunity cycle and immune CPI response and resistance}

The clinical trials and utility of CPIs have provided key insights into the potential mechanisms of anticancer immune therapies that may underlie cancer immune escape (26). A seven-step event in an anticancer immune response, known as the cancer-immunity cycle (27), is required to be initiated and to sequentially lead to the effective killing of cancercells. In the last step, the dead cancer cells will release further tumor-associated antigens and cycle again to increase the strength of the immune response in subsequent cycle revolutions. However, the cancer-immunity cycle does not function as aforementioned in patients with cancer. The anticancer function of effector $\mathrm{T}$ cells may not respond properly, owing to the factors in the tumor microenvironment (TME) (28) as indicated in Fig. 1A. At the early stage, the tumor possesses a lower TMB/fewer neo-Ags (29). Subsequently, the tumor appears to induce a greater TMB/more neo-Ags through the loss of mismatch repair and DNA instability, enhancing the immunity of cancer, and ultimately leading to activation of tumor neo-Ag-specific cluster of differentiation (CD) $8^{+} \mathrm{T}$ cells and immune-mediated tumor cell death (30-33). Heterogeneity, relevance of neo-Ag burden and importance of clonal vs. subclonal neo-Ag in patients with early-stage NSCLC, included in The Cancer Genome Atlas project, have been assessed (34). Generally, the human body has an immunoregulatory mechanism, known as immune checkpoint, including CTLA4 and PD-1/PD-L1 (35). Using this pathway, the tumor evades the lethal effects of the immune system, therefore neo-Ags, including driver/passenger, serve an important role in this progress. Inhibiting the immune checkpoint and killing the clonal or subclonal neo-Ag-specific tumor cells are useful ways to unlock the suppressed lethal response to tumors (36). Monoclonal antibodies against the PD-1/PD-L1 pathway (Table I), have been proved to improve outcomes in patients with $\operatorname{NSCLC}(6,11-13,37)$, including patients who have relapsed following treatment with platinum-based first-line chemotherapy or tyrosine kinase inhibitor therapy (Fig. 1B). The clinical trial of nivolumab in resectable NSCLC (trial no. NCT02259621), investigates the safety, feasibility and effects of nivolumab in this patient population (38). Neoadjuvant nivolumab was indicated to have fewer side effects, to not require any delay in surgery and to induce a major pathological response in $45 \%$ of resected tumors (38). Combining immunotherapies with chemotherapy or radiotherapy may lead to an improved response in various patients. One reason for this observation was that cytotoxic chemotherapies and radiation may induce a greater number of novel subclonal mutations that are associated with the response to immunotherapy (39). Furthermore, the immune TME (iTME) will be evaluated or assessed to a greater extent by immune signature/immunogenomic analysis, including quantification of infiltrated $\mathrm{CD} 8^{+} \mathrm{T}$ cells, though immunohistochemistry (IHC) assay, and their TCR analysis, including next-generation sequencing (NGS) $(40,41)$.

\section{Biomarkers associated with liquid biopsy for lung cancer immunotherapy}

Currently, liquid biopsy, in particular ctDNA, can indicate better tumor heterogeneity at a greater accuracy compared with tumor biopsy, since it facilitates a convenient and dynamic analysis $(42,43)$. The question is how liquid biopsies can be utilized for immunotherapy. As for immunotherapy, liquid biopsies may be useful for monitoring ctDNA and the response of the immune system in vivo, for example, the analysis of circulating free DNA (cfDNA) released from distinct $\mathrm{T}$ cell clones, on the basis of the assessment of B cell receptor and TCR immune repertoire from blood plasma (44). The dynamic variation in the cfDNA (45) or $\mathrm{T}$ cell-surface markers in the blood (46) may provide clues to the type of treatments that have a higher probability to be effective for each patient. Further study of TME is required, in order to identify suitable biomarkers for liquid biopsy, in particular the iTME. Histologically, the primary tumors can be broadly categorized into two classes: Inflamed or uninflamed $(26,47,48)$. A subset of immune-associated genes, including $\mathrm{CD} 8 \alpha / \beta$, interferon (IFN) $-\gamma$ and granzyme (GZM) A, B and $\mathrm{H}$ that were upregulated in the high clonal neo-Ag group, was revealed by gene expression analysis, indicating an inflammatory TME (49). The expression of these genes was countered by the upregulation of immune checkpoints, including PD-1, PD-L1 and PD-L2. The immune CPIs indicated a high efficacy against inflamed tumors, owing to their sufficient infiltration by cytotoxic $\mathrm{T}$ cells that recognize cancer-specific antigens or neo-Ags, high density of IFN- $\gamma$-producing $\mathrm{CD}^{+} \mathrm{T}$ cells, expression of PD-L1 in tumor-infiltrating immune cells, possible genomic instability, and the presence of a pre-existing antitumor immune response (50). However, they have not been indicated to be effective against uninflamed tumors, which are immunologically unknown, are poorly infiltrated by lymphocytes, rarely express PD-L1, and are characterized by highly proliferating tumors with low TMB and low expression of antigen-presentation machinery markers, including major histocompatibility complex (MHC) class I (51-53). 
A
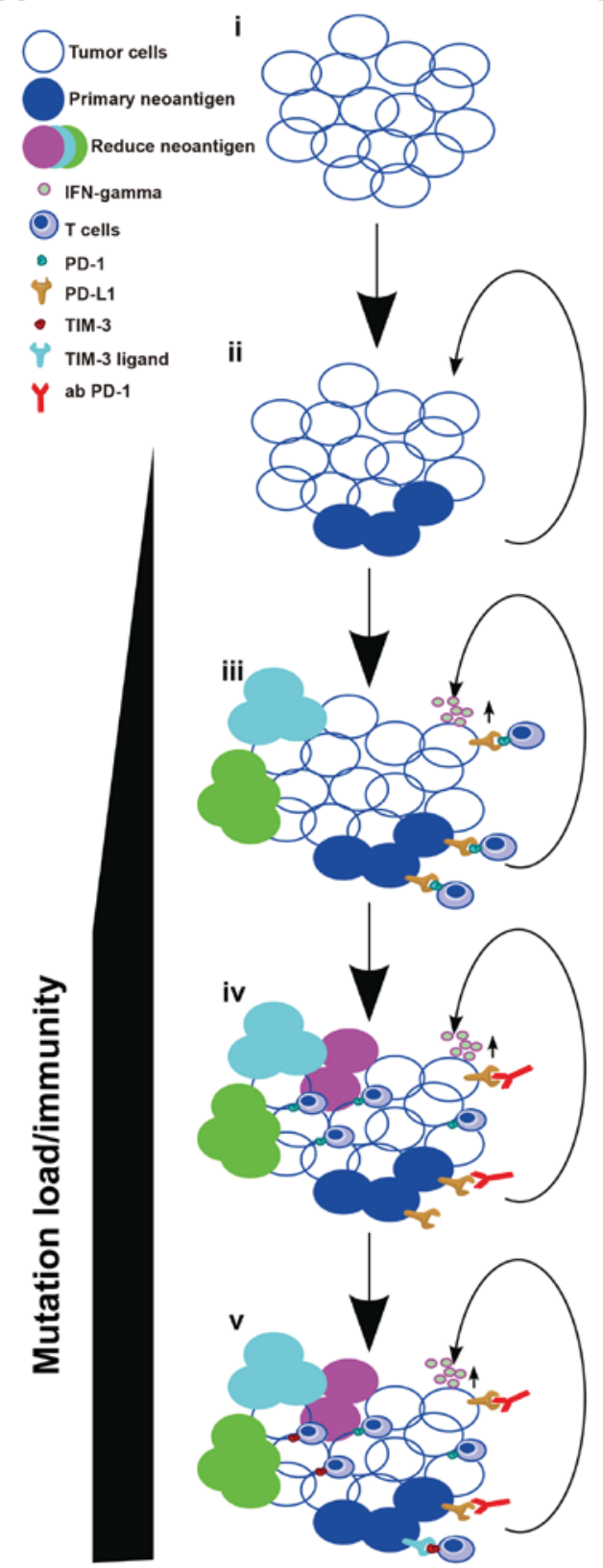

B

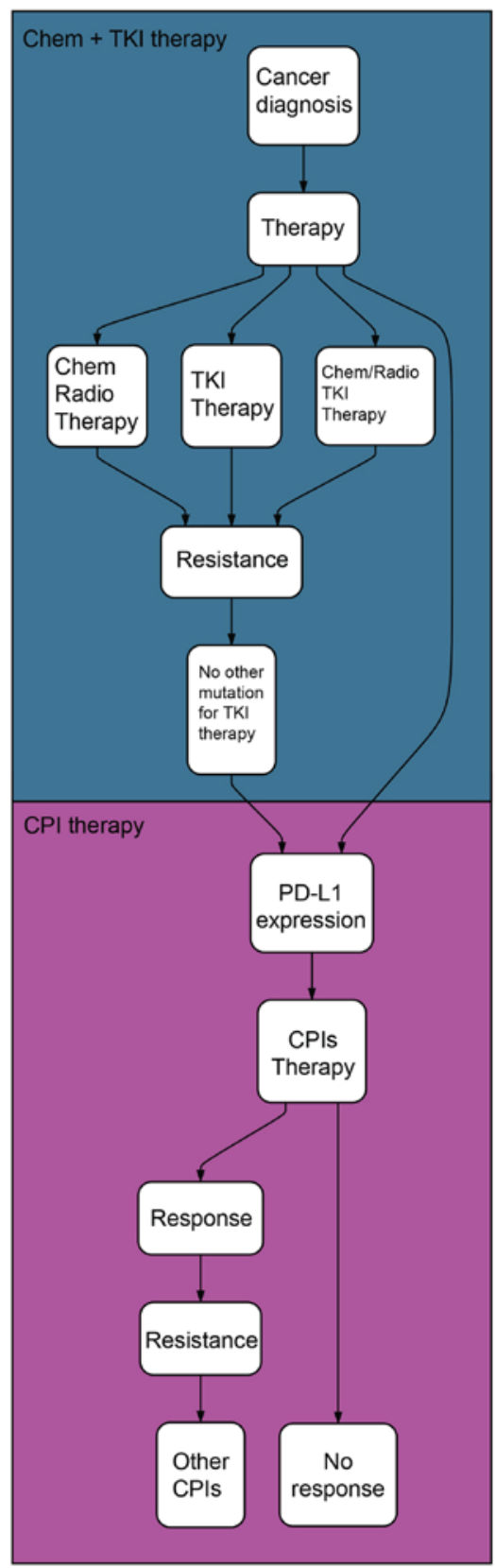

Figure 1. Cancer-immunity cycle and immune checkpoint inhibitor resistance. (A) CPI resistance on the cancer-immunity cycle and TMB/neo-Ags i) Early-stage cancer without/with fewer neo-Ags. ii) Cancer within major neo-Ags. iii) For resistance of immune response for major neo-Ag, cancer induces an increase in neo-Ags to render cancer less susceptible to the immune system. The CPIs will give a clinical response at this stage. iv) The CPIs, including anti-PD-1, are used. v) Adaptive resistance with upregulation of alternative immune checkpoints-TIM-3. The circular arrow indicates the cancer-immunity cycle. (B) Clinical therapy strategy using chemo-, TKI and CPI. CPI, checkpoint inhibitor; neo-Ag, neoantigen; TMB, tumor mutation burden; TKI, tyrosine kinase inhibitor; PD-1, programmed death receptor-1; PD-L1, PD-1 ligand 1; chem, chemotherapy; radio, radiotherapy; TIM-3, T cell immunoglobulin-3; IFN- $\gamma$, interferon $\gamma ; a b$, antibody.

According to a useful pragmatic framework reported by Teng et al (54) and Smyth et al (55), TME can be stratified into four types: Type I [tumor-infiltrating lymphocyte (TIL)+, PD-L1+], Type II (TILs-, PD-L1-), Type III (TIL-, PD-L1+) and Type IV (TIL+, PD-L1-) (Fig. 2A). Researchers have attempted to use this classification for lung cancer immunotherapy, in order to provide an explanation for its contribution of its poor prognosis (56-58). Biomarkers associated with distinguishing the four types of iTME will be beneficial to clinical cancer management of individualized and precise cancer treatment.
According to the use of CTLA4, PD-L1 and PD-1, co-inhibitory receptor targets, including lymphocyte activating 3 (59), T cell immunoglobulin-3 (TIM-3) (60) and $\mathrm{T}$ cell immunoglobulin and ITIM domain (61), which are safer and less toxic (62), are being investigated in clinical trials. Adaptive resistance to anti-PD-1 therapy is associated with the upregulation of TIM-3 expression in lung cancer (63). Patients with cancer may receive more optimal effects when receiving the anti-TIM-3 agent. The expression level of PD-L2, GZMA and human leukocyte antigens A has indicated that these factors are novel potential biomarkers for predicting the 


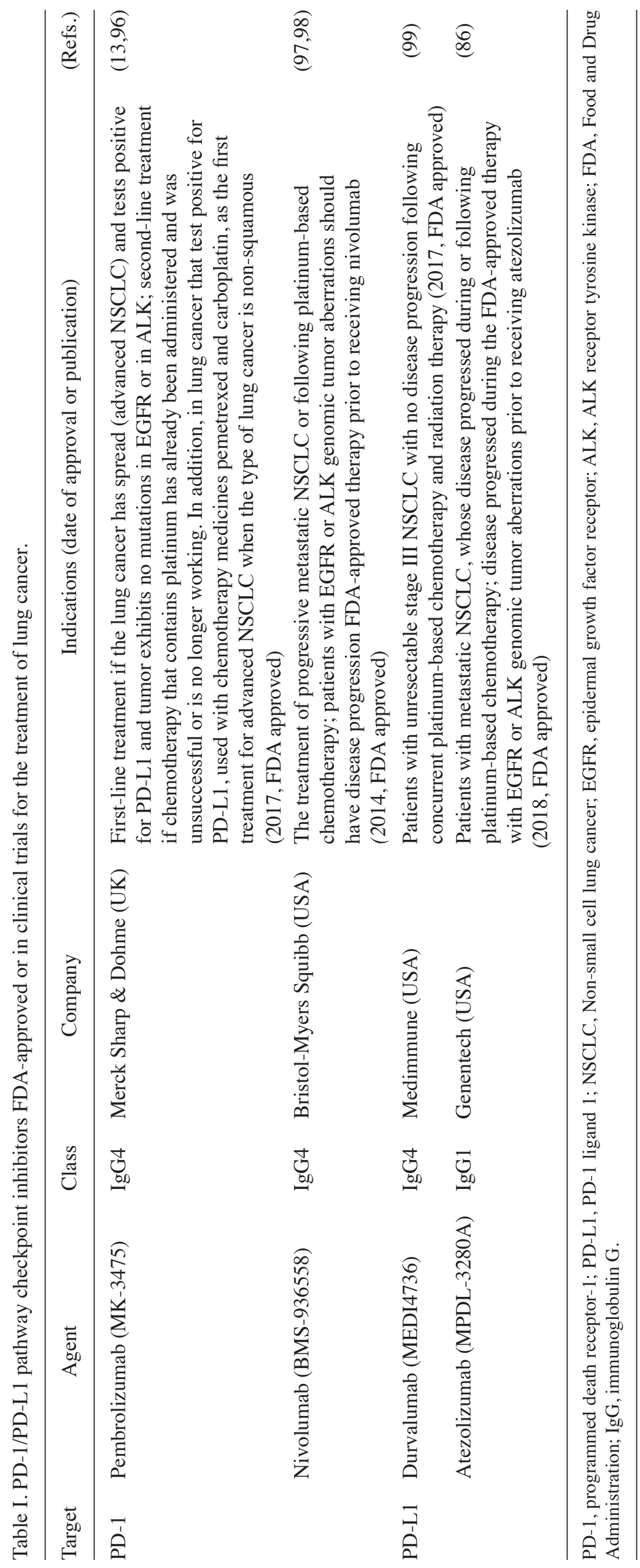


A

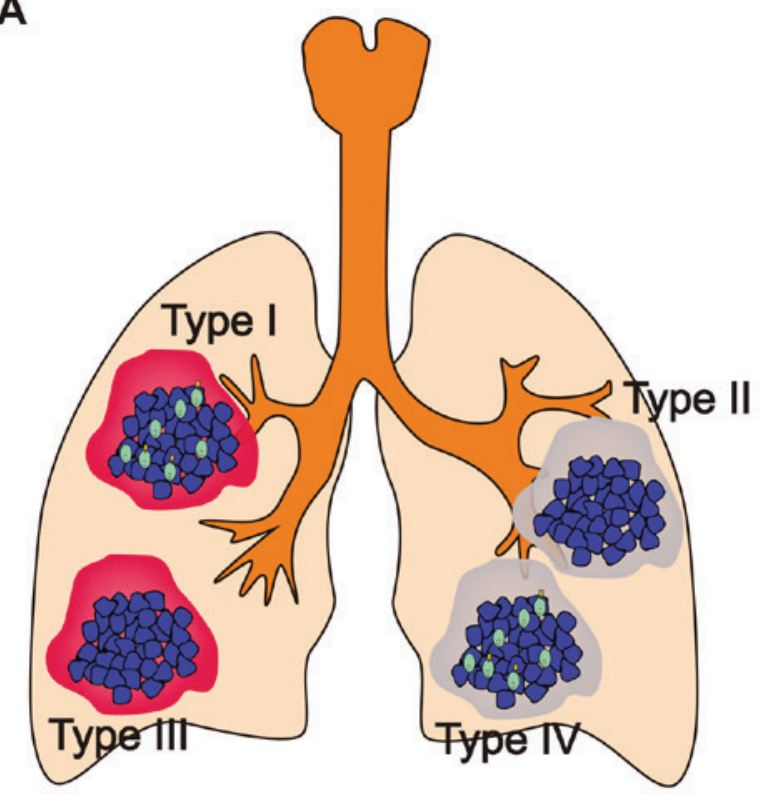

Type I: PD-L1+, TILs(+)

Type II: PD-L1-, TILs(-)

Type III: PD-L1+, TILs(-)

Type IV: PD-L1-, TILs(+)

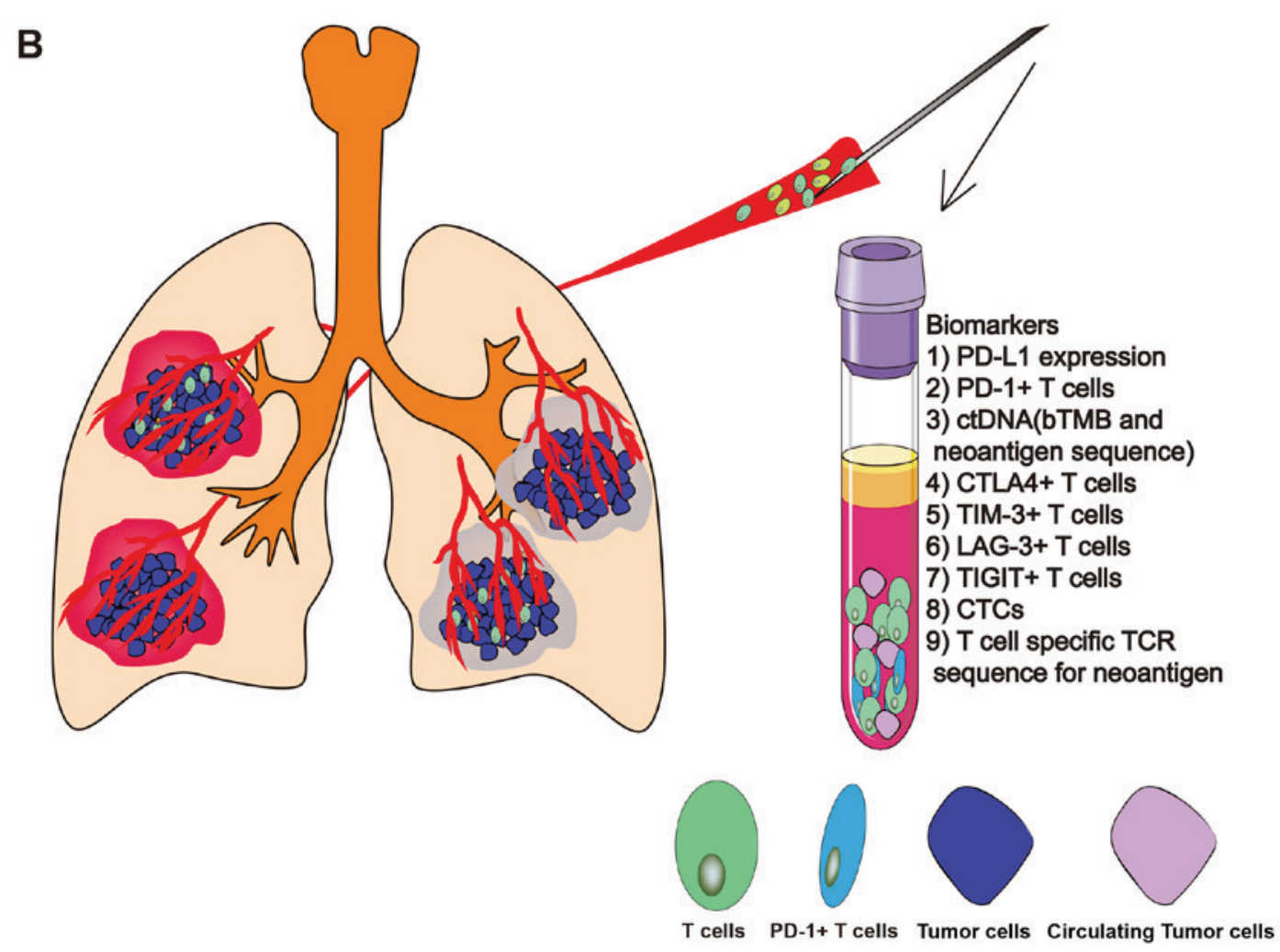

Figure 2. Liquid biopsy for cancer immunotherapy based on PD-1 checkpoint inhibitor in lung cancer. (A) The four types of lung cancer, according to the immune status of tumor microenvironment: Type I, PD-L1+ with TIL+, indicating adaptive immune resistance; Type II, PD-L1- with TIL-, indicating immune ignorance; Type III, PD-L1+ with TIL-, indicating intrinsic induction in iTME; Type IV, PD-L1- with TIL+, indicating the role of other suppressor pathways in promoting immune tolerance. (B) Biomarkers associated with iTME in blood samples. With liquid biopsy by blood sample, the PD-L1 expression, including soluble PD-L1 and cell-free PD-L1 RNA, and surface biomarker expression (i.e., CTLA4, PD-1, LAG-3, TIM-3) on circulating T cells, provide a window into the antitumor reactivity of T cells in the TME. CTCs, ctDNA and cfDNA were used for the detection of TMB or bTMB. TIL, tumor-infiltrating lymphocyte; PD-1, programmed death receptor-1; TIM-3, hepatitis A virus cellular receptor 2; iTME, immune tumor microenvironment; CTLA4, cytotoxic T-lymphocyte-associated protein 4; CTCs, positive circulating tumor cells; ctDNA, circulating tumor DNA; cfDNA, circulating free DNA; TMB, tumor mutation burden; TCR, T-cell receptor; LAG-3, lymphocyte activating 3.

effective response for CPIs in pre-anti-PD-1 antibody-treatment (nivolumab) melanoma tissues (50). Gros et al (64) reported that mutation-specific T cells may be isolated from blood in $75 \%$ of patients with melanoma. This study was focused on melanoma; however, it is becoming clear that immunotherapies can be used to treat numerous types of cancer, including lung cancer. These mutation-specific $\mathrm{T}$ cells have made it possible to determine the neo-Ag status of tumors from blood, and they may serve as a liquid biopsy technique for cancer immunotherapy or a novel immunotherapy (41). In Fig. 2B, the biomarkers associated with 


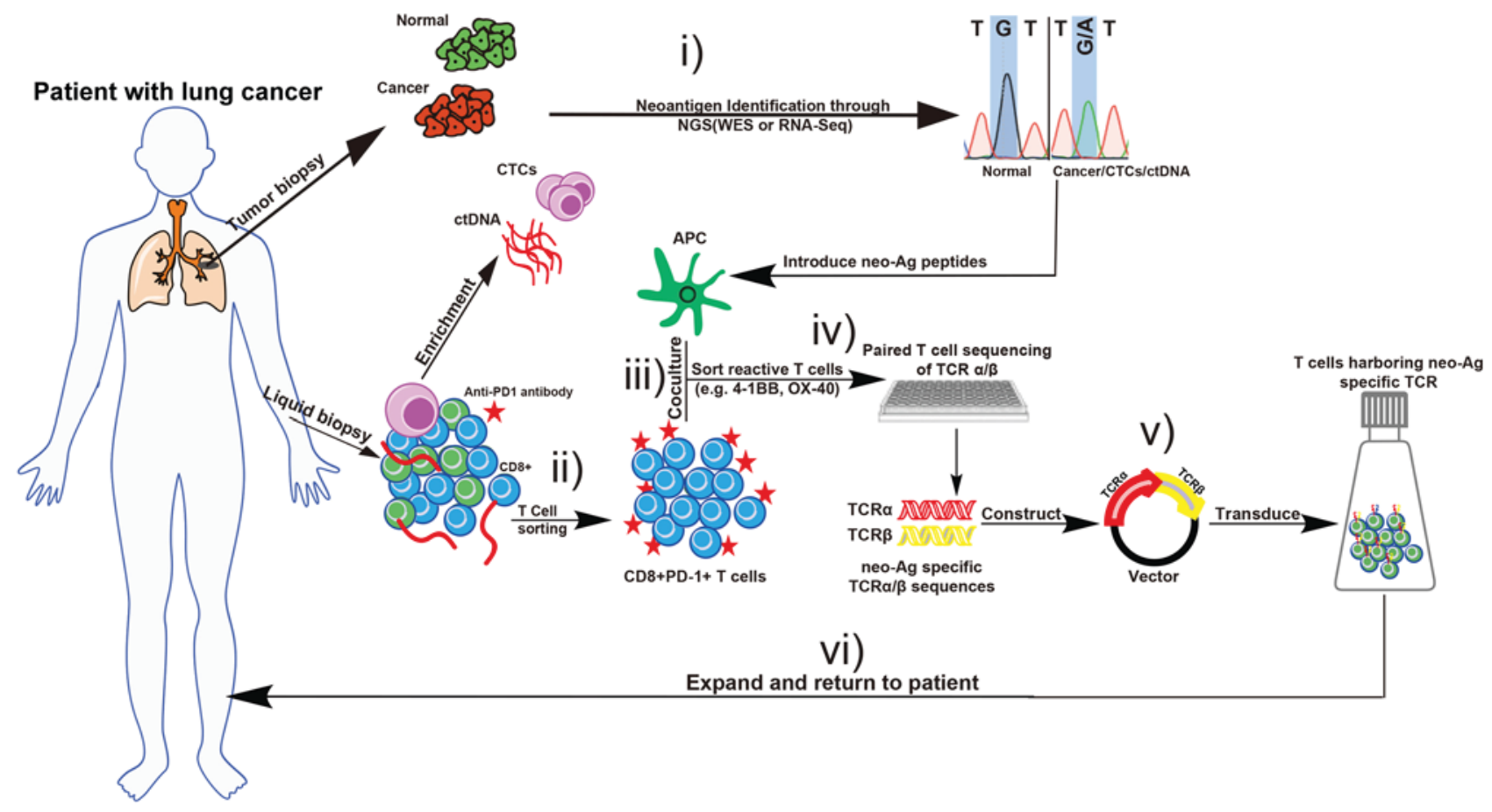

Figure 3. TCR-engineered adoptive therapy targeting neoantigen in patients with lung cancer. i) Primary tumor biopsy or CTCs/ctDNA enriched from liquid biopsy, underwent whole-exome sequencing and RNA sequencing to identify non-synonymous somatic mutations or neo-Ags. ii) CD8+/PD-1+ T cells were sorted by flow cytometry. iii) Sorted CD8+/PD-1+ T cells were co-cultured with antigen-presenting cells with synthetic long peptides of neo-Ag. iv) T cells with upregulated activation markers, including $4-1 \mathrm{BB}, \mathrm{OX}-40$, were isolated and underwent paired TCR sequencing to identify TCR $\alpha / \beta$ sequences against neo-Ag. v) T cells isolated from the blood cells of the same patient were modified with the transfect vector to encode the identified TCR $\alpha / \beta$. In this process, the patients' T cells acquired tumor-specificity that allowed them to attack cancer with specific neo-Ag. vi) Modified T cells were cultured and expanded in vitro to obtain sufficient numbers for the treatment and reinfusion into the same patient with cancer. TCR, T-cell receptor; CTCs, positive circulating tumor cells; ctDNA, circulating tumor DNA; neo-Ags, neoantigens; PD-1, programmed death receptor-1; NGS, next-generation sequencing; WES, whole exome sequencing; OX-40, tumor necrosis factor superfamily member 4; 4-1BB, tumor necrosis factor receptor superfamily member 9; CD, cluster of differentiation.

iTME are depicted, which may be used in liquid biopsy for lung cancer immunotherapy. The detection of PD-L1 $1^{+}$circulating tumor cells (CTCs) in patients with NSCLC treated with the PD-1 inhibitor nivolumab indicated that CTCs was a good liquid biopsy material associated with immunotherapy (65). At the American Association for Cancer Research Annual Meeting 2018, data from the CheckMate-227 trial indicated that the first-line treatment of nivolumab and ipilimumab in combination has improved progression-free survival (7.2 months) compared with chemotherapy (5.5 months) for patients with advanced NSCLC with high TMB (66). The importance of TMB detection makes blood-based TMB (bTMB) a considerable clinical biomarker (67). Using ctDNA, bTMB analysis may be performed more easily and at a higher rate, as indicated by the clinical outcomes stratified by bTMB in the POPLAR (clincaltrials.gov. no. NCT01903993) and OAK (clincaltrials. gov. no. NCT02008227) clinical trials (68), which assessed the efficacy of anti-PD-L1 CPI (atezolizumab) for recurrent advanced NSCLC. In this meeting, another trial (clinicaltrials. gov no. KEYNOTE-189) reported an improvement in overall survival by 8.8 months in the pembrolizumab-combination group and 4.9 months in the placebo-combination group across all PD-L1 categories that were evaluated, indicating the key role of PD-L1 detection in CPI therapy. In another trial (clincaltrials. gov. no. NCT02259621), TMB was used as an indicator of the pathological response to anti-PD-1 CPI therapy (38). At between 2 and 4 weeks after neoadjuvant nivolumab treatment, rapid expansion of mutation-associated neo-Ag-specific T-cell clones, from a primary tumor, along with a positive pathological assessment, was detected in peripheral blood in $8 / 9$ patients assessed. A number of these clones were not detected prior to the administration of anti-PD-1 CPI (nivolumab).

\section{TCR-engineered adoptive therapy targeting neo-Ags for lung cancer}

Immunotherapies are developed to help strengthen the immune attack against tumor cells. One approach is CPIs, as aforementioned, and the other is TCR-engineered adoptive therapy $(64,69)$. The increased sensitivity of the sequencing method allows for the detection of early-stage lung cancer by means of cfDNA analysis, as this technique will provide additional information about patients with cancer after a radiological screening method. Rizvi et al (70) indicated that a smoking signature and neo-Ags in the tumor were factors, which were associated with the response to anti-PD-1 CPI. It has been reported that tumor regression was associated with a neo-Ag-specific response by $\mathrm{CD}^{+} \mathrm{T}$ cells (71). The accumulated evidence indicates that the genomic characteristics of a tumor may potentially assist in selecting and customizing immunotherapy. Consistent with these data, researchers have also been able to identify tumor-infiltrating $\mathrm{CD}^{+} \mathrm{T}$ cells reactive to clonal neo-Ags in patients with NSCLC with homogenous and heterogeneous early-stage tumors (72). Adoptive T cell therapy was developed further in a number of ways on the basis of current knowledge. First, the $\mathrm{CD} 8^{+} / \mathrm{PD}-1^{+}$ 
T cell subset, which was isolated and expanded from peripheral blood, was reinfused into the patient with cancer (41). Using high-throughput screening platforms, including NGS and high-performance liquid chromatography-mass spectrometry (HPLC-MS), neo-Ag-specific T cells in the PD-1+ T cells may be identified, and may be used with their respective TCRs in immunotherapy (73). Another method of identification is the combination of HPLC-MS and sequencing, where novel neo-Ags can be identified (74). The focus of the study of Khodadoust et al (75) was on direct proteomic analysis of cancer MHC ligands and epitopes, using HPLC-MS rather than simply performing whole exome sequencing (WES) of DNA to identify tumor-associated non-synonymous somatic mutations. Neo-Ags are personalized antigens, except for certain common oncogene-specific antigens, including the KRAS proto-oncogene. A summary of TCR-engineered adoptive therapy targeting neo-Ags for lung cancer is presented in Fig. 3. The deep sequencing on tumor tissue, CTCs or ctDNA is used to determine the potential neo-Ags and TCR, in order to identify the sequences of the most dominant clonotypes within the PD- $1^{+} \mathrm{T}$ cell subset. CTCs, a liquid biopsy material, can be enriched from the blood using a number of methods, including microfluidic isolation based on the epithelial cell adhesion molecule expression (76). This may be another way of obtaining neo-Ags from CTCs, based on NGS, since they provide more information about the primary or metastatic tumor sites.

\section{Discussion and conclusions}

Immunotherapy serves a key role in lung cancer therapy. CPIs have already been used for lung cancer therapy in various locations, including United States (77) and China (78). However, novel therapies targeting CPIs, including anti-CTLA4, anti-PD-1 and anti-PD-L1, are changing the prognosis of patients with advanced lung cancer. Randomized trials have reported improvements in OS compared with standard treatments, including chemotherapy and radiotherapy $(6,11,13,77-81)$. Since there are biomarkers suitable for use in immunotherapy, a great deal of attention has been drawn to the assessment of PD-1 or PD-L1 expression in TME, challenged by the difficulty of accessing tissue samples, heterogeneity and the lack of gold-standard antibodies for IHC staining (82). WES for determination of TMB in liquid biopsy from patients with advanced NSCLC suggests that liquid biopsy-derived TMB may be used as a useful biomarker for predicting the CPI response, particularly in cases where tumor biopsy is not accessible or has been resampled (83). Theoretically, there are numerous potential biomarkers for immunotherapy in liquid biopsy; however, to the best of our knowledge, none has been identified to be reliable enough, particularly with respect to evaluating their efficiency or even their selection following drug resistance. It is important to identify liquid biopsy biomarkers for prognostic and response prediction associated with CPIs to guide future clinical decisions.

Successes with CPIs in the second-line treatment of NSCLCs have inevitably led to trials in the first-line setting (11). However, not all patients have reported an effective response. In clinical trials, patients who have presented with immunogenic tumors, including high TMB or neo-Ags, and pre-existing intratumoral immune infiltrate and immune escape ligands (i.e., PD-1/PD-L1) being targeted, seem to benefit the most from CPI therapy. As the first approved IHC assay for anti-PD-1 (pembrolizumab) in NSCLC, the PD-L1 (22C3) diagnostic (Dako PD-L1 IHC 22C3 pharmDx) $(84,85)$ is still a key biomarker for the selection of patients with cancer (86). Pembrolizumab had been used as the first-line treatment (87), instead of cytotoxic chemotherapy, in patients with lung cancer whose proportion score for PD-L1 was $\geq 50 \%$ in TME (88). However, activating the immune system also presents with its own risks, since the immune CPIs give rise to grade 3/4 immune-associated adverse events (irAEs) with ipilimumab (15-25\%), permbrolizumab $(13 \%)$ and nivolumab $(14 \%)(89,90)$. It is therefore necessary to elucidate the immune status in individual patients with cancer to identify a predictive method for these irAE risks. Biomarkers associated with these CPIs that predict efficacy, prognosis or risk of irAE risk may assist in the identification of patients who may benefit from these therapies. Biomarkers associated with clinical response prediction and the acquired resistance monitoring of lung cancer immunotherapy may be assessed in a dynamic manner using liquid biopsy based on blood samples, which would be beneficial to patients. However, extensive further investigation is required for the practical application of this treatment, largely due to the limitations of its sensitivity.

Although neo-Ag vaccines or TCR-engineered T cells targeting neo-Ags can be used for the majority of patients with cancer, the truly but rare tumor-specific $\mathrm{T}$ cells among the selected subset, may limit the therapeutic utility of $\mathrm{T}$ cell products (91). Therefore, more comprehensive technologies, including NGS, TCR sequencing and HPLC-MS are required. Furthermore, current methods for predicting tumor neo-Ags remain at an early stage and are limited by class I rather than class II MHC antigens (92). Additional efforts are required in the development of MHC class I- and class II-restricted neo-Ags as these will provide additional information about the immune surveillance in tumor development. The neo-Ag identification can be classified into direct and reverse identification using different techniques (93). The direct identification requires validation by exome and transcriptome sequencing data, whereas the MS-based reverse identification allows the identification of $\mathrm{CD}^{+}$and $\mathrm{CD}^{+}{ }^{+} \mathrm{T}$-cell neo-epitopes (29). However, to the best of our knowledge, the capacity of neo-Ag identification by direct identification has yet to be improved. It may eventually serve as a key tool in antigen discovery.

Lung cancer has entered the era of personalized immunotherapy (94,95). An improved understanding of the mechanisms of immunotherapies in patients with cancer will assist in the identification of biomarkers, suitable for the patients who will benefit the most from the treatment. Understanding the dynamics and diversity of these mechanisms will provide additional knowledge for when and how these therapeutic strategies should be utilized to prolong the effective response of immunotherapy in patients with NSCLC and therefore improving their outcomes.

\section{Acknowledgements}

Not applicable. 


\section{Funding}

The present study was supported by the National Natural Sciences Foundation Key Program (grant no. 81630071), the Aiyou Foundation (grant no. KY201701) and the Ministry of Education Innovation Team development project (grant no. IRT-17R10).

\section{Availability of data and materials}

Not applicable.

\section{Authors' contributions}

LLC and JW wrote the review, and have read and approved the final version of this manuscript.

\section{Ethics approval and consent to participate}

Not applicable.

\section{Patient consent for publication}

Not applicable.

\section{Competing interests}

The authors declare that they have no competing interests.

\section{References}

1. Cameron F, Whiteside G and Perry C: Ipilimumab: First global approval. Drugs 71: 1093-1104, 2011.

2. Hodi FS, Lawrence D, Lezcano C, Wu X, Zhou J, Sasada T, Zeng W, Giobbie-Hurder A, Atkins MB, Ibrahim N, et al: Bevacizumab plus ipilimumab in patients with metastatic melanoma. Cancer Immunol Res 2: 632-642, 2014.

3. Topalian SL, Hodi FS, Brahmer JR, Gettinger SN, Smith DC, McDermott DF, Powderly JD, Carvajal RD, Sosman JA, Atkins MB, et al: Safety, activity, and immune correlates of anti-PD-1 antibody in cancer. N Engl J Med 366: 2443-2454, 2012.

4. Wolchok JD, Kluger H, Callahan MK, Postow MA, Rizvi NA, Lesokhin AM, Segal NH, Ariyan CE, Gordon RA, Reed K, et al Nivolumab plus ipilimumab in advanced melanoma. N Engl J Med 369: 122-133, 2013.

5. Larkin J, Chiarion-Sileni V, Gonzalez R, Grob JJ, Cowey CL, Lao CD, Schadendorf D, Dummer R, Smylie M, Rutkowski P, et al: Combined nivolumab and ipilimumab or monotherapy in untreated melanoma. N Engl J Med 373: 23-34, 2015.

6. Borghaei H, Paz-Ares L, Horn L, Spigel DR, Steins M, Ready NE, Chow LQ, Vokes EE, Felip E, Holgado E, et al: Nivolumab versus docetaxel in advanced nonsquamous non-small-cell lung cancer. N Engl J Med 373: 1627-1639, 2015.

7. Powles T, Eder JP, Fine GD, Braiteh FS, Loriot Y, Cruz C, Bellmunt J, Burris HA, Petrylak DP, Teng SL, et al: MPDL3280A (anti-PD-L1) treatment leads to clinical activity in metastatic bladder cancer. Nature 515: 558-562, 2014.

8. Chen L and Han X: Anti-PD-1/PD-L1 therapy of human cancer: Past, present, and future. J Clin Invest 125: 3384-3391, 2015.

9. Herbst RS, Soria JC, Kowanetz M, Fine GD, Hamid O, Gordon MS, Sosman JA, McDermott DF, Powderly JD, Gettinger SN, et al: Predictive correlates of response to the anti-PD-L1 antibody MPDL3280A in cancer patients. Nature 515: 563-567, 2014.

10. Garon EB, Rizvi NA, Hui R, Leighl N, Balmanoukian AS, Eder JP, Patnaik A, Aggarwal C, Gubens M, Horn L, et al: Pembrolizumab for the treatment of non-small-cell lung cancer. N Engl J Med 372: 2018-2028, 2015.
11. Brahmer J, Reckamp KL, Baas P, Crino L, Eberhardt WE, Poddubskaya E, Antonia S, Pluzanski A, Vokes EE, Holgado E, et al: Nivolumab versus docetaxel in advanced squamous-cell non-small-cell lung cancer. N Engl J Med 373: 123-135, 2015.

12. Rizvi NA, Mazieres J, Planchard D, Stinchcombe TE, Dy GK, Antonia SJ, Horn L, Lena H, Minenza E, Mennecier B, et al: Activity and safety of nivolumab, an anti-PD-1 immune checkpoint inhibitor, for patients with advanced, refractory squamous non-small-cell lung cancer (CheckMate 063): A phase 2, single-arm trial. Lancet Oncol 16: 257-265, 2015.

13. Herbst RS, Baas P, Kim DW, Felip E, Perez-Gracia JL, Han JY, Molina J, Kim JH, Arvis CD, Ahn MJ, et al: Pembrolizumab versus docetaxel for previously treated, PD-L1-positive, advanced non-small-cell lung cancer (KEYNOTE-010): A randomised controlled trial. Lancet 387: 1540-1550, 2016.

14. Borghaei $\mathrm{H}$ and Brahmer J: Nivolumab in nonsquamous non-small-cell lung cancer. N Engl J Med 374: 493-494, 2016.

15. Fehrenbacher L, Spira A, Ballinger M, Kowanetz M, Vansteenkiste J, Mazieres J, Park K, Smith D, Artal-Cortes A, Lewanski C, et al: Atezolizumab versus docetaxel for patients with previously treated non-small-cell lung cancer (POPLAR): A multicentre, open-label, phase 2 randomised controlled trial. Lancet 387: 1837-1846, 2016.

16. Brahmer JR, Tykodi SS, Chow LQ, Hwu WJ, Topalian SL, Hwu P, Drake CG, Camacho LH, Kauh J, Odunsi K, et al: Safety and activity of anti-PD-L1 antibody in patients with advanced cancer. N Engl J Med 366: 2455-2465, 2012.

17. Spigel DR, Schrock AB, Fabrizio D, Frampton GM, Sun J and He J: Total mutation burden (TMB) in lung cancer (LC) and relationship with response to $\mathrm{PD}-1 / \mathrm{PD}-\mathrm{L} 1$ targeted therapies. Am Soc Clin Oncol 2016.

18. Anagnostou V, Smith KN, Forde PM, Niknafs N, Bhattacharya R, White J, Zhang T, Adleff V, Phallen J, Wali N, et al: Evolution of neoantigen landscape during immune checkpoint blockade in non-small cell lung cancer. Cancer Discov 7: 264-276, 2017.

19. Vitale SG, Lagana AS, Capriglione S, Angioli R, La Rosa VL, Lopez S, Valenti G, Sapia F, Sarpietro G, Butticè S, et al: Target therapies for uterine carcinosarcomas: Current evidence and future perspectives. Int J Mol Sci 18: E1100, 2017.

20. Bai H, Mao L, Wang HS, Zhao J, Yang L, An TT, Wang X, Duan CJ, Wu NM, Guo ZQ, et al: Epidermal growth factor receptor mutations in plasma DNA samples predict tumor response in Chinese patients with stages IIIB to IV non-small-cell lung cancer. J Clin Oncol 27: 2653-2659, 2009.

21. Bai H, Wang Z, Chen K, Zhao J, Lee JJ, Wang S, Zhou Q, Zhuo M, Mao L, An T, et al: Influence of chemotherapy on EGFR mutation status among patients with non-small-cell lung cancer. J Clin Oncol 30: 3077-3083, 2012.

22. Aparicio $\mathrm{S}$ and Caldas $\mathrm{C}$ : The implications of clonal genome evolution for cancer medicine. N Engl J Med 368: 842-851, 2013.

23. Aguiar PN Jr, De Mello RA, Barreto CMN, Perry LA, Penny-Dimri J, Tadokoro H and Lopes GL Jr: Immune checkpoint inhibitors for advanced non-small cell lung cancer: Emerging sequencing for new treatment targets. ESMO Open 2: e000200, 2017.

24. Alexander W: European society for medical oncology 2016 congress. P T 41: 796-800, 2016.

25. Cyriac G and Gandhi L: Emerging biomarkers for immune checkpoint inhibition in lung cancer. Semin Cancer Biol 52: 269-277, 2018.

26. Hegde PS, Karanikas V and Evers S: The where, the when, and the how of immune monitoring for cancer immunotherapies in the era of checkpoint inhibition. Clin Cancer Res 22: 1865-1874, 2016.

27. Chen DS and Mellman I: Oncology meets immunology: The cancer-immunity cycle. Immunity 39: 1-10, 2013.

28. Kim R, Emi M and Tanabe K: Cancer immunoediting from immune surveillance to immune escape. Immunology 121: 1-14, 2007.

29. Bobisse S, Foukas PG, Coukos G and Harari A: Neoantigen-based cancer immunotherapy. Ann Transl Med 4: 262, 2016.

30. Miller A, Asmann Y, Cattaneo L, Braggio E, Keats J, Auclair D, Lonial S MMRF CoMMpass Network, Russell SJ and Stewart AK: High somatic mutation and neoantigen burden are correlated with decreased progression-free survival in multiple myeloma. Blood Cancer J 7: e612, 2017.

31. Turajlic S, Litchfield K, Xu H, Rosenthal R, McGranahan N, Reading JL, Wong YNS, Rowan A, Kanu N, Al Bakir M, et al: Insertion-and-deletion-derived tumour-specific neoantigens and the immunogenic phenotype: A pan-cancer analysis. Lancet Oncol 18: 1009-1021, 2017. 
32. Tran E, Robbins PF and Rosenberg SA: 'Final common pathway' of human cancer immunotherapy: Targeting random somatic mutations. Nat Immunol 18: 255-262, 2017.

33. Tran E, Turcotte S, Gros A, Robbins PF, Lu YC, Dudley ME, Wunderlich JR, Somerville RP, Hogan K, Hinrichs CS, et al: Cancer immunotherapy based on mutation-specific CD4+ T cells in a patient with epithelial cancer. Science 344: 641-645, 2014.

34. McGranahan N, Furness AJ, Rosenthal R, Ramskov S, Lyngaa R, Saini SK, Jamal-Hanjani M, Wilson GA, Birkbak NJ, Hiley CT, et al: Clonal neoantigens elicit $\mathrm{T}$ cell immunoreactivity and sensitivity to immune checkpoint blockade. Science 351 : 1463-1469, 2016.

35. Jenkins RW, Barbie DA and Flaherty KT: Mechanisms of resistance to immune checkpoint inhibitors. Br J Cancer 118: 9-16, 2018.

36. McGranahan $\mathrm{N}$ and Swanton C: Clonal heterogeneity and tumor evolution: Past, present, and the future. Cell 168: 613-628, 2017.

37. Reck M, Bondarenko I, Luft A, Serwatowski P, Barlesi F, Chacko R, Sebastian M, Lu H, Cuillerot JM and Lynch TJ: Ipilimumab in combination with paclitaxel and carboplatin as first-line therapy in extensive-disease-small-cell lung cancer: Results from a randomized, double-blind, multicenter phase 2 trial. Ann Oncol 24: 75-83, 2013.

38. Forde PM, Chaft JE and Pardoll DM: Neoadjuvant PD-1 blockade in resectable lung cancer. N Engl J Med 379: e14, 2018.

39. Samstein RM and Riaz N: The DNA damage response in immunotherapy and radiation. Adv Radiat Oncol 3: 527-533, 2018.

40. Nakamura Y: Immunopharmacogenomics: Springer Japan 483 p, 2015.

41. Schumacher TN and Scheper W: A liquid biopsy for cancer immunotherapy. Nat Med 22: 340-341, 2016.

42. Heitzer E, Ulz P and Geigl JB: Circulating tumor DNA as a liquid biopsy for cancer. Clin Chem 61: 112-123, 2015.

43. Cheng F, Su L and Qian C: Circulating tumor DNA: A promising biomarker in the liquid biopsy of cancer. Oncotarget 7 : 48832-48841, 2016

44. Akyuz N, Brandt A, Stein A, Schliffke S, Mahrle T, Quidde J, Goekkurt E, Loges S, Haalck T, Ford CT, et al: T-cell diversification reflects antigen selection in the blood of patients on immune checkpoint inhibition and may be exploited as liquid biopsy biomarker. Int J Cancer 140: 2535-2544, 2017.

45. Gedvilaitė V, Schveigert D and Cicenas S: Cell-free DNA in non-small cell lung cancer. Acta Med Litu 24: 138-144, 2017.

46. Mingari MC and Moretta L: Surface markers of human T lymphocytes. Ric Clin Lab 12: 439-448, 1982.

47. Gajewski TF: The next hurdle in cancer immunotherapy: Overcoming the Non-T-Cell-inflamed tumor microenvironment. Semin Oncol 42: 663-671, 2015.

48. Sharma P and Allison JP: The future of immune checkpoint therapy. Science 348: 56-61, 2015.

49. Inoue H, Park JH, Kiyotani K, Zewde M, Miyashita A, Jinnin M, Kiniwa Y, Okuyama R, Tanaka R, Fujisawa Y, et al: Intratumoral expression levels of PD-L1, GZMA, and HLA-A along with oligoclonal $\mathrm{T}$ cell expansion associate with response to nivolumab in metastatic melanoma. Oncoimmunology 5 : e1204507, 2016.

50. Duan J, Wang Y and Jiao S: Checkpoint blockade-based immunotherapy in the context of tumor microenvironment: Opportunities and challenges. Cancer Med 7: 4517-4529, 2018.

51. Alexandrov LB, Nik-Zainal S, Wedge DC, Aparicio SA, Behjati S, Biankin AV, Bignell GR, Bolli N, Borg A, Børresen-Dale AL, et al: Signatures of mutational processes in human cancer. Nature 500: 415-421, 2013.

52. Kandoth C, McLellan MD, Vandin F, Ye K, Niu B, Lu C, Xie M Zhang Q, McMichael JF, Wyczalkowski MA, et al: Mutational landscape and significance across 12 major cancer types. Nature 502: 333-339, 2013.

53. Kinoshita $\mathrm{Y}$, Ishiguro $\mathrm{T}$, Sano $\mathrm{Y}$, Azuma $\mathrm{Y}$, Tsunenari $\mathrm{T}$, Ono $\mathrm{N}$ Kayukawa Y, Ueda O, Wada NA, Hino H, et al: Anti-GPC3 TRAB, a first-in-class T cell-redirecting bispecific antibody targeting glypican-3 with potent in vitro and in vivo antitumor efficacy against solid tumors. Cancer Research 76: 1482, 2016

54. Teng MW, Ngiow SF, Ribas A and Smyth MJ: Classifying Cancers Based on T-cell Infiltration and PD-L1. Cancer Res 75: 2139-2145, 2015

55. Smyth MJ, Ngiow SF, Ribas A and Teng MW: Combination cancer immunotherapies tailored to the tumour microenvironment. Nat Rev Clin Oncol 13: 143-158, 2016.
56. Konishi J, Yamazaki K, Azuma M, Kinoshita I, Dosaka-Akita H and Nishimura M: B7-H1 expression on non-small cell lung cancer cells and its relationship with tumor-infiltrating lymphocytes and their PD-1 expression. Clin Cancer Res 10: 5094-5100, 2004.

57. Kawai O, Ishii G, Kubota K, Murata Y, Naito Y, Mizuno T, Aokage K, Saijo N, Nishiwaki Y, Gemma A, et al: Predominant infiltration of macrophages and CD8(+) T Cells in cancer nests is a significant predictor of survival in stage IV nonsmall cell lung cancer. Cancer 113: 1387-1395, 2008.

58. Mu CY, Huang JA, Chen Y, Chen C and Zhang XG: High expression of PD-L1 in lung cancer may contribute to poor prognosis and tumor cells immune escape through suppressing tumor infiltrating dendritic cells maturation. Med Oncol 28: 682-688, 2011.

59. He Y, Yu H, Rozeboom L, Rivard CJ, Ellison K, Dziadziuszko R, Suda K, Ren S, Wu C, Hou L, et al: LAG-3 protein expression in non-small cell lung cancer and its relationship with PD-1/PD-L1 and tumor-infiltrating lymphocytes. J Thorac Oncol 12: 814-823, 2017.

60. Zhang Y, Cai P, Liang T, Wang L and Hu L: TIM-3 is a potential prognostic marker for patients with solid tumors: A systematic review and meta-analysis. Oncotarget 8: 31705-31713, 2017.

61. Liu XG, Hou M and Liu Y: TIGIT, a novel therapeutic target for tumor immunotherapy. Immunol Invest 46: 172-182, 2017.

62. Anderson AC, Joller N and Kuchroo VK: Lag-3, Tim-3, and TIGIT: Co-inhibitory receptors with specialized functions in immune regulation. Immunity 44: 989-1004, 2016.

63. Koyama S, Akbay EA, Li YY, Herter-Sprie GS, Buczkowski KA Richards WG, Gandhi L, Redig AJ, Rodig SJ, Asahina H, et al: Adaptive resistance to therapeutic PD-1 blockade is associated with upregulation of alternative immune checkpoints. Nat Commun 7: 10501, 2016.

64. Gros A, Parkhurst MR, Tran E, Pasetto A, Robbins PF, Ilyas S, Prickett TD, Gartner JJ, Crystal JS, Roberts IM, et al: Prospective identification of neoantigen-specific lymphocytes in the peripheral blood of melanoma patients. Nat Med 22: 433-438, 2016.

65. Nicolazzo C, Raimondi C, Mancini M, Caponnetto S, Gradilone A, Gandini O, Mastromartino M, Del Bene G, Prete A, Longo F, et al: Monitoring PD-L1 positive circulating tumor cells in non-small cell lung cancer patients treated with the PD-1 inhibitor Nivolumab. Sci Rep 6: 31726, 2016.

66. Hellmann MD, Ciuleanu TE, Pluzanski A, Lee JS, Otterson GA, Audigier-Valette C, Minenza E, Linardou H, Burgers S, Salman P, et al: Nivolumab plus ipilimumab in lung cancer with a high tumor mutational burden. N Engl J Med 378: 2093-2104, 2018.

67. Gandara DR, Paul SM, Kowanetz M, Schleifman E, Zou W, Li Y, Rittmeyer A, Fehrenbacher L, Otto G, Malboeuf C, et al: Blood-based tumor mutational burden as a predictor of clinical benefit in non-small-cell lung cancer patients treated with atezolizumab. Nat Med 24: 1441-1448, 2018.

68. Gandara DR, Kowanetz M, Mok TSK, Rittmeyer A, Fehrenbacher L, Fabrizio D, Otto G, Malboeuf C, Lieber D, Paul SM, et al: 1295OBlood-based biomarkers for cancer immunotherapy: Tumor mutational burden in blood (bTMB) is associated with improved atezolizumab (atezo) efficacy in 2L+ NSCLC (POPLAR and OAK). Ann Oncol 28 (Suppl 5), 2017.

69. Rosenberg SA and Restifo NP: Adoptive cell transfer as personalized immunotherapy for human cancer. Science 348: 62-68, 2015.

70. Rizvi NA, Hellmann MD, Snyder A, Kvistborg P, Makarov V, Havel JJ, Lee W, Yuan J, Wong P, Ho TS, et al: Cancer immunology. Mutational landscape determines sensitivity to PD-1 blockade in non-small cell lung cancer. Science 348: 124-128, 2015.

71. Durgeau A, Virk Y, Corgnac S and Mami-Chouaib F: Recent advances in targeting CD8 T-Cell immunity for more effective cancer immunotherapy. Front Immunol 9: 14, 2018.

72. Pasetto A, Gros A, Robbins PF, Deniger DC, Prickett TD, Matus-Nicodemos R, Douek DC, Howie B, Robins H, Parkhurst MR, et al: Tumor-and neoantigen-reactive T-cell receptors can be identified based on their frequency in fresh tumor. Cancer Immunol Res 4: 734-743, 2016.

73. Bassani-Sternberg M and Coukos G: Mass spectrometry-based antigen discovery for cancer immunotherapy. Curr Opin Immunol 41: 9-17, 2016

74. Caron E, Kowalewski DJ, Chiek Koh C, Sturm T, Schuster H and Aebersold R: Analysis of major histocompatibility complex (MHC) immunopeptidomes using mass spectrometry. Mol Cell Proteomics 14: 3105-3117, 2015. 
75. Khodadoust MS, Olsson N, Wagar LE, Haabeth OA, Chen B, Swaminathan K, Rawson K, Liu CL, Steiner D, Lund P, et al: Antigen presentation profiling reveals recognition of lymphoma immunoglobulin neoantigens. Nature 543: 723-727, 2017.

76. Cai LL, Ye HM, Zheng LM, Ruan RS and Tzeng CM: Circulating tumor cells (CTCs) as a liquid biopsy material and drug target. Curr Drug Targets 15: 965-972, 2014.

77. Rizvi NA, Hellmann MD, Brahmer JR, Juergens RA, Borghaei H, Gettinger S, Chow LQ, Gerber DE, Laurie SA, Goldman JW, et al: Nivolumab in combination with platinum-based doublet chemotherapy for first-line treatment of advanced non-small-cell lung cancer. J Clin Oncol 34: 2969-2979, 2016.

78. Liu SY and Wu YL: Ongoing clinical trials of PD-1 and PD-L1 inhibitors for lung cancer in China. J Hematol Oncol 10: 136 2017.

79. Motzer RJ, Escudier B, McDermott DF, George S, Hammers HJ, Srinivas S, Tykodi SS, Sosman JA, Procopio G, Plimack ER, et al: Nivolumab versus everolimus in advanced renal-cell carcinoma. N Engl J Med 373: 1803-1813, 2015.

80. Robert C, Long GV, Brady B, Dutriaux C, Maio M, Mortier L, Hassel JC, Rutkowski P, McNeil C, Kalinka-Warzocha E, et al: Nivolumab in previously untreated melanoma without BRAF mutation. N Engl J Med 372: 320-330, 2015.

81. Ribas A, Puzanov I, Dummer R, Schadendorf D, Hamid O, Robert C, Hodi FS, Schachter J, Pavlick AC, Lewis KD, et al: Pembrolizumab versus investigator-choice chemotherapy for ipilimumab-refractory melanoma (KEYNOTE-002): A randomised, controlled, phase 2 trial. Lancet Oncol 16: 908-918, 2015.

82. Chen Q, Li T and Yue W: Drug response to PD-1/PD-L1 blockade: Based on biomarkers. Onco Targets Ther 11: 4673-4683, 2018

83. Koeppel F, Blanchard S, Jovelet C, Genin B, Marcaillou C, Martin E, Rouleau E, Solary E, Soria JC, André F and Lacroix L: Whole exome sequencing for determination of tumor mutation load in liquid biopsy from advanced cancer patients. PLoS One 12: e0188174, 2017.

84. Ilie M, Khambata-Ford S, Copie-Bergman C, Huang L, Juco J, Hofman V and Hofman P: Use of the 22C3 anti-PD-L1 antibody to determine PD-L1 expression in multiple automated immunohistochemistry platforms. PLoS One 12: e0183023, 2017.

85. Marchetti A, Barberis M, Franco R, De Luca G, Pace MV, Staibano S, Volante M, Buttitta F, Guerini-Rocco E, Righi L, et al: Multicenter comparison of 22c3 pharmDx (Agilent) and SP263 (Ventana) assays to test PD-L1 expression for NSCLC patients to be treated with immune checkpoint inhibitors. J Thoracic Oncol 12: 1654-1663, 2017.

86. Kowanetz M, Koeppen H, Zou W, Mariathasan S, Hellmann M, Kockx M, Chappey C, Kadel E, Smith D, Miley N, et al: Abstract A017: PD-L1 as a predictive biomarker for atezolizumab (MPDL3280A; anti-PDL1) in non-small cell lung cancer (NSCLC). AACR; 2016.

87. Hu X and Hay JW: First-line pembrolizumab in PD-L1 positive non-small-cell lung cancer: A cost-effectiveness analysis from the UK health care perspective. Lung Cancer 123: 166-171, 2018.
88. Dang TO, Ogunniyi A, Barbee MS and Drilon A: Pembrolizumab for the treatment of PD-L1 positive advanced or metastatic non-small cell lung cancer. Expert Rev Anticancer Ther 16: 13-20, 2016.

89. Ibrahim RA, Berman DM, Depril V, Humphrey RW, Chen T and Messina M: Ipilimumab safety profile: Summary of findings from completed trials in advanced melanoma. J Clin Oncol 29 (15-Suppl): 8583, 2011.

90. Teply BA and Lipson EJ: Identification and management of toxicities from immune checkpoint-blocking drugs. Oncology (Williston Park) 3 (28 Suppl): 30-38, 2014.

91. Efremova M, Finotello F, Rieder D and Trajanoski Z: Neoantigens generated by individual mutations and their role in cancer immunity and immunotherapy. Front Immunol 8: 1679, 2017.

92. Wilson EA and Anderson KS: Lost in the crowd: Identifying targetable MHC class I neoepitopes for cancer immunotherapy. Expert Rev Proteomics 15: 1065-1077, 2018.

93. Bassani-Sternberg M, Bräunlein E, Klar R, Engleitner T, Sinitcyn P, Audehm S, Straub M, Weber J, Slotta-Huspenina J, Specht K, et al: Direct identification of clinically relevant neoepitopes presented on native human melanoma tissue by mass spectrometry. Nat Commun 7: 13404, 2016.

94. Klebanoff CA, Rosenberg SA and Restifo NP: Prospects for gene-engineered $\mathrm{T}$ cell immunotherapy for solid cancers. Nat Med 22: 26-36, 2016.

95. Politi K and Herbst RS: Lung cancer in the era of precision medicine. Clin Cancer Res 21: 2213-2220, 2015.

96. Ramalingam S, Hui R, Gandhi L, Carcereny E, Felip E, Ahn MJ, Eder JP, Balmanoukian AS, Leighl N, Aggarwal C, et al: P2. 39: Long-Term OS for patients with advanced NSCLC enrolled in the KEYNOTE-001 study of pembrolizumab. J Thoracic Oncol 11: S241-S242, 2016

97. Gettinger S, Rizvi NA, Chow LQ, Borghaei H, Brahmer J, Ready N, Gerber DE, Shepherd FA, Antonia S, Goldman JW, et al: Nivolumab monotherapy for first-line treatment of advanced non-small-cell lung cancer. J Clin Oncol 34: 2980-2987, 2016.

98. Forde PM, Smith KN, Chaft JE, Hellmann M, Merghoub T, Wolchok JD, Yang SC, Battafarano RJ, Gabrielson E, Georgiades CS, et al: NSCLC, early stageNeoadjuvant anti-PD1, nivolumab, in early stage resectable non-small-cell lung cancer. Ann Oncol 27(Suppl 6): LBA41-PR, 2016.

99. Antonia S, Rizvi N, Brahmer JR, Ou SHL, Khleif SN, Hwu WJ, Gutierrez M, Schoffski P, Hamid O, Weiss J, et al: Abstract A047: Safety and clinical activity of durvalumab (MEDI4736), an anti-programmed cell death ligand-1 (PD-L1) antibody, in patients with non-small cell lung cancer (NSCLC). AACR; 2016.

(i) $($ ) This work is licensed under a Creative Commons Attribution-NonCommercial-NoDerivatives 4.0 International (CC BY-NC-ND 4.0) License. 